\title{
May Biochemical Variables and Pleural Fluid Cell Count Be Used in the Benign-Malign Differentiation of Pleural Effusions Associated with Lung Cancer?
}

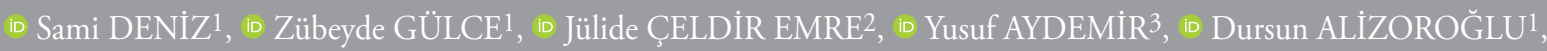 \\ iD Ahmet Emin ERBAYCU1 \\ IUniversity of Health Sciences, İzmir Dr. Suat Seren Chest Diseases and Chest Surgery Training and Research Hospital, Clinic of Chest \\ Diseases, İzmir, Turkey \\ ${ }^{2}$ Turgutlu State Hospital, Clinic of Chest Diseases, Manisa, Turkey \\ 3Sakarya University Faculty of Medicine, Department of Chest Diseases, Sakarya, Turkey
}

\begin{abstract}
Objective: Pleural effusion is frequently encountered in patients with lung cancer. Malignant-benign differentiation of the fluid is very important for treatment decision because malignant fluid is considered as the inoperability criterion. However, this distinction is not clinically feasible and may require a cytological examination of the fluid via invasive procedures. The aim of this study was to determine whether there was any difference between laboratory results of malignant and benign pleural fluids.

Methods: We retrospectively evaluated 135 patients with cytologically diagnosed lung cancer and underwent benign-malignant differentiation of pleural effusion. Benign and malignant groups were compared in terms of fluid biochemistry, blood gas and cell count.

Results: One hundred four patients were male, 31 were female and the mean age was $63.5 \pm 11.4$ years. Histologically adenocarcinoma was determined as the most common (56\%). Right pleural effusion was present in $58.5 \%$ of the patients. Malignant effusion rate was higher in females (malign/benign; female: 21/10, male: 48/56). Albumin, protein, erythrocyte count (RBC) and hematocrit (HCT) values in pleural fluid were higher in the malignant group $(\mathrm{p}=0.001, \mathrm{p}=0.018, \mathrm{p}=0.009$ and, $\mathrm{p}=0.016$, respectively). Cut-off value for albumin: 2.85 and odds ratio (OR): 2.02; for HCT 4.7 and OR: 6.25; for RBC 300 and OR: 6.25; for protein 4.45 and OR: 2.08.

Conclusion: In our study, we found that the values of albumin, HCT, RBC and protein in pleural fluid were higher in malignant pleural effusion.
\end{abstract}

Keywords: Pleural effusion, lung cancer, fluid biochemistry

\section{Introduction}

Pleural effusion is a common clinical problem that can occur due to systemic, pulmonary, and pleural pathologies (1). Evaluation of effusion in terms of transudate-exudate helps to differentiate systemic and pulmonary causes. The effusion in the form of transudate is often formed due to systemic causes such as congestive heart failure and liver cirrhosis, while the effusion in the form of exudate can occur during the course of both malignant and benign lung diseases. Approximately $42-72 \%$ of all exudative effusions develop secondary to malignant diseases $(2,3)$. All cancers, especially lung cancers, metastasize to pleura and can cause effusion formation. In the initial evaluation of patients with lung cancer, pleural effusion is present in approximately 15\% of the patients. During the course of the disease, in $50 \%$ of the patients with diffuse lung cancer, pleural effusion develops (4). 
Detection of malignant pleural effusion in a patient with lung cancer is considered as $\mathrm{M} 1 \mathrm{a}$ in staging and means stage 4 (inoperable) cancer (5). However, every effusion detected in patients with cancer is not malignant. Pleural effusion can develop due to secondary causes without malignant pleural involvement in lung cancer. These effusions, called as paramalign effusions, are not considered as malignant pleurisy. Paramalign effusion can also be seen due to postobstructive pneumonia, atelectasis, chilotorax, pulmonary embolism and hypoproteinemia (6). Therefore, in a patient with cancer, the differentiation between benign and malign effusion is of great importance. In order to achieve the correct diagnosis, fluid or tissue samples taken from the pleural space should undergo cyto/histopathological examination. However, this distinction is not always easy. The proportion of patients getting a diagnosis with various analyses of pleural fluid sample, including cytological examination, is between $50-60 \%$ and it may be necessary to obtain pleural tissue with invasive methods (2).

In this study, it was aimed to investigate the contribution of biochemical tests and cell analysis performed as standard procedures in pleural fluid sample before invasive methods in the separation of paramalign (benign)-malignant pleural effusion.

\section{Methods}

\section{Patient Selection}

The study was designed as a retrospective case series. The study was carried out in patients with lung cancer and pleural effusion who were followed up for the last 5 years. One hundred and thirty five patients with cytologic diagnosis of lung cancer, with an accompanying exudative pleural effusion of which benignmalignant separation was definitively made cytologically (thoracentesis was performed at least 2 times and in addition closed biopsy was performed) and in which biochemical tests, blood gas test and cell count were performed, were included in the study. Patients with chylothorax, pseudochylothorax, pleural effusion in the form of transudate and empyema were excluded: one patient with chylothorax had a history of prior trauma, in 1 patient with pseudochylothorax, it was detected that the patient had pleural fluid before the diagnosis of lung cancer, the content of fluid was intense in patients with empyema, pleural effusion in the form of transudate was related with additional diseases and was not related with lung cancer. Age, sex, type of lung cancer, cytology of fluid, blood gas, biochemistry (albumin, lactate dehydrogenase, protein), erythrocyte count (RBC), hematocrit (HTC) value, and cell count were recorded in all patients. Biochemical tests were performed with Roche-Hitachi Cobas 8000 and 6000, blood gas with Radiometer ABL 700 and hemogram with Beckman-Coulter AV 47160 LH 780 devices. Cytologic examination of fluids was performed as follows: fluid samples, taken by thoracentesis, were centrifuged at $700 \mathrm{rpm}$ in Cytospin 4 device for 5 minutes following being painted with Giemsa and hematoxylin and eosin. This study was approved by the University of Health Sciences, İzmir Dr. Suat Seren Chest Diseases and Chest Surgery Training and Research Hospital, Clinic of Chest Diseases (number: 49109414/806.02.02).

\section{Statistical Analysis}

Statistical analysis was performed using SPSS 18. In all comparisons, type 1 error margin was determined as alpha: 0.05 and was tested in two directions. Chi-square test was used to compare categorical variables and Mann-Whitney $U$ test was used to compare continuous variables. The receiver operating characteristic (ROC) curve analysis was performed and cut-off values were determined for variables of biochemical and cell count tests that were found significant. Specificity and sensitivity values were given in the diagnostic tests, according to these cutoff values.

\section{Results}

One hundred four males and 31 females were included in the study and the mean age of the patients was $63.58 \pm 11.45$ years. There was no difference between malignant and benign groups in terms of gender and location of pleural effusion $(p=0.057$ and $\mathrm{p}=0.20$, respectively) (Table 1$)$.

Pleural effusion albumin level $[1.91 \pm 0.88$ vs $2.3 \pm 0.61 \mathrm{gr} / \mathrm{dL}$ $(\mathrm{p}=0.001)]$, protein level $[3.7 \pm 1.4$ vs $4.2 \pm 1 \mathrm{gr} / \mathrm{dL}(\mathrm{p}=0.018)]$, RBC [58.1 \pm 174 vs $393 \pm 641 \quad(\mathrm{p}=0.009)]$ and HTC level $[1.3 \pm 3.08$ vs $3.79 \pm 5.38(\mathrm{p}=0.016)]$ were significantly higher in the malignant group than in the benign group. There was no significant difference between the benign and malignant groups in terms of other biochemical tests, arterial blood gas, hemogram and age (Table 2).

Table 1. Demographic features and etiologies of the patients

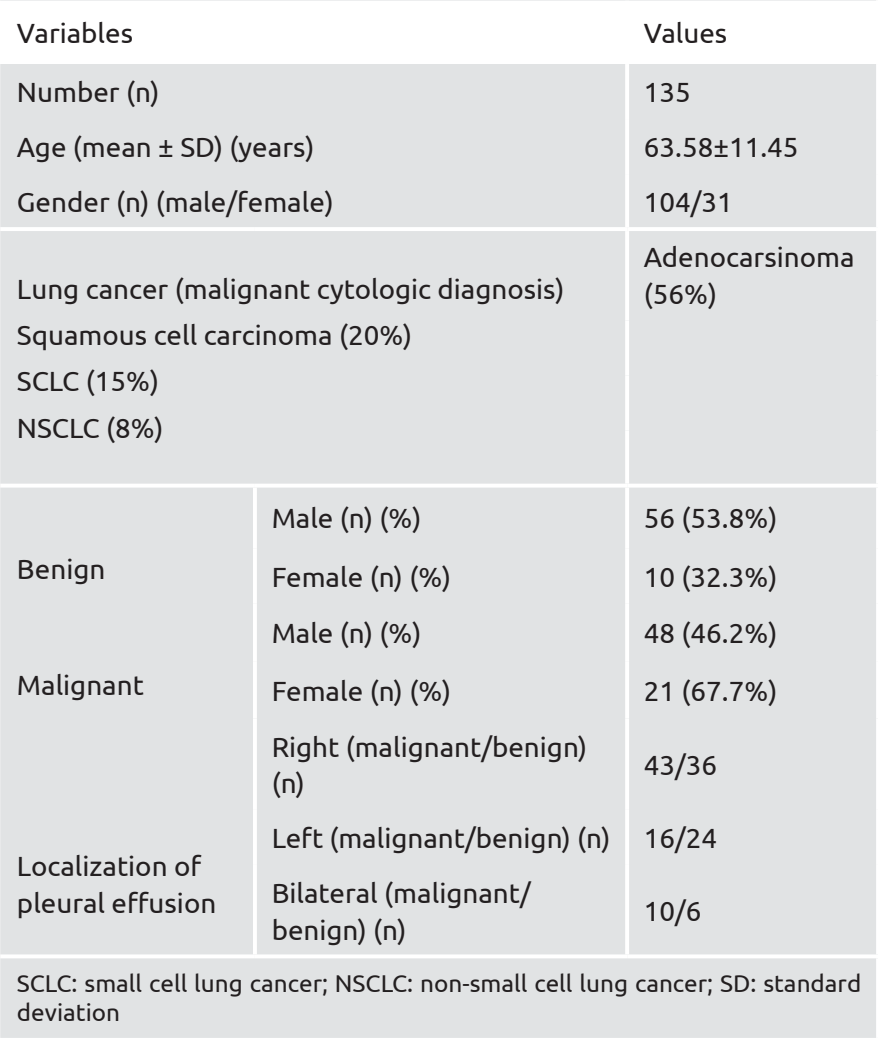


Table 2. Intra-group means and intergroup comparisons

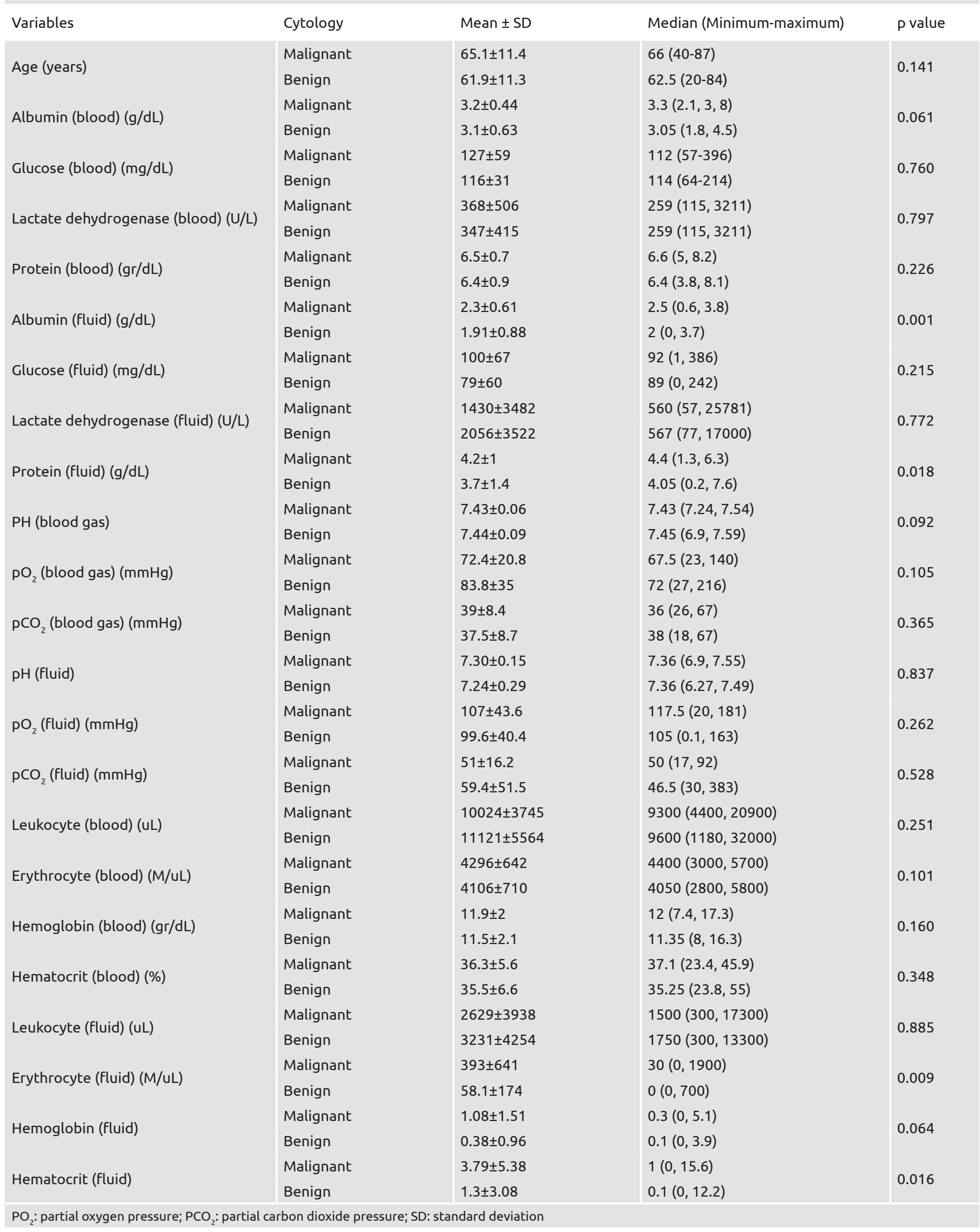


Table 3. Sensitivity and specifity values for albumin, hematocrit, protein and erythrocyte

\begin{tabular}{|l|l|l|l|l|l|}
\hline Variables & Cut-off value & Sensitivity (\%) & Specifity (\%) & PPV (\%) & NPV (\%) \\
\hline Albumin & 2.85 & 80.6 & 10.61 & 47.79 & 35.00 \\
\hline Protein & 4.45 & 50.72 & 31.82 & 43.75 & 16.18 \\
\hline Erythrocyte & 300 & 70.59 & 6.25 & 44.44 & 16.67 \\
\hline Hematocrit & 4.7 & 70.59 & 6.25 & 44.44 & \\
\hline
\end{tabular}

PPV: positive predictive value; NPV: negative predictive value

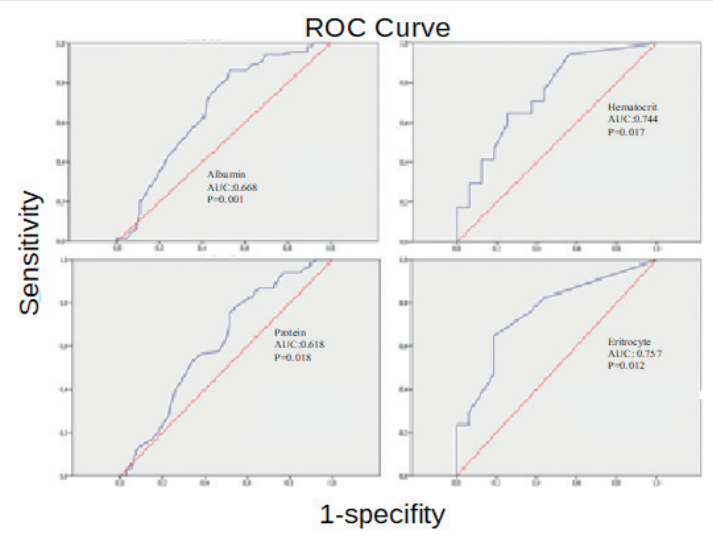

Figure 1. Threshold values for albumin, hematocrit, protein and erythrocyte

ROC: receiver operating characteristics

The cut-off value for albumin was 2.85 and odds ratio (OR): 2.02, for HTC 4.7 and OR: 6.25, for RBC 300 and OR: 6.25, for protein 4.45 and OR: 2.08 (Figure 1).

Among determined variables, the highest sensitivity was found in albumin $(80.6 \%)$ and the highest specifity was found in protein (31.82\%) (Table 3).

\section{Discussion}

Malignant pleural effusions are one of the most common causes of exudative pleural fluids; approximately $42-72 \%$ of all exudative fluids develop secondary to malignant diseases (2). Lung cancer causes $40-50 \%$ of all malignant pleural effusions. Cancer metastasizes to pleura by lymphatic or hematogenous way or by direct invasion. However, it is not yet clear by which mechanism cancer cells cause the formation of fluid in the pleura. The most common accepted mechanisms are increased vascular permeability and impaired drainage $(7,8)$.

Macroscopic features of malignant pleural effusion are not specific. Malignant pleural effusion may be serous, serosanguinous, or hemorrhagic. Hemorrhagic effusions suggest direct pleural involvement. Serous effusion often occurs after lymphatic obstruction or atelectasis due to endobronchial lesion. In all studies conducted to date, tumor markers and other biochemical tests in pleural fluid have been shown to be inadequate in differential diagnosis. Besides, it is stated that biochemical analysis is not reliable in the differentiation between malignant and bening (9). Therefore, cytological examination is used to differentiate malignant from benign pleural effusions. However, in only half of patients, malignant cells are detected in cytological examination (10). Advanced invasive procedures are required for patients who cannot be diagnosed with cytological examination. Although macroscopic appearance of fluid does not have a diagnostic role, it is likely that hemorrhagic and exudative fluids are malignant. Therefore, in patients with lung cancer, exudative and hemorrhagic fluids should be considered as malignant fluids unless proven otherwise (11). In our study, it was found that in pleural fluid, increased albumin and protein levels which were associated with exudate and increased RBC and HTC levels which were associated with hemorrhagic appearance increased the likelihood of malignant effusions. $\mathrm{P}$ values for albumin, protein, RBC and HTC were $\mathrm{p}=0.001, \mathrm{p}=0.018$, $\mathrm{p}=0.009$ and $\mathrm{p}=0.016$, respectively.

In approximately one-third of patients with malignant pleural effusion, at time of diagnosis, $\mathrm{pH}$ of pleural effusion varies from 6.95 to 7.29 and glucose concentration is low (10). In our study, we found that $\mathrm{pH}$ was more acidic in malignant effusions but statistically there was no difference between benign and malignant groups in terms of $\mathrm{pH}$ of effusion $(\mathrm{p}=0.837)$. Also, there was no difference between benign and malignant groups in terms of glucose of effusion.

Although lung cancer is more common in males, malignant pleural effusion is more common in females $(12,13)$. In our study, we found that malignant pleural effusion was more frequent in females than in male patients, although we had more males than females. Malignant effusion was detected in $68 \%$ of females and $46 \%$ of males in our study.

Pleural effusion associated with malignant disease is usually seen over 50 years of age $(14,15)$. When age trends of patients with malignant effusion were examined, $83 \%$ of patients were reported to be over 50 years of age (2). In our study, the mean age was 65 years in patients with malignant effusion, while the mean age was 62 years in patients with benign effusion, but the difference was not significant.

The diagnostic value of cytologic examination of pleural effusion varies according to the type of cancer. The highest diagnostic value was in adenocarcinoma, and this rate was lower in squamous cell carcinoma (16). Adenocarcinoma was found in $56 \%$, squamous cell carcinoma in $20 \%$ and small cell carcinoma in $15 \%$ of our patients. 
When evaluated in terms of the placement of effusion, $62.5 \%$ of bilateral effusions, $54.4 \%$ of right effusions and $40 \%$ of left effusions were found to be malignant. In total, higher rate of malignancy in pleural effusions in the right side could be explained by the fact that much more of lymphatic drainage of the lung is drained to the right side.

In our study, cut-off values were calculated by using ROC curve analysis for albumin, protein, RBC and hemotocrit, which were statistically significant in malignant effusions. As expected, sensitivity and specificity values in all parameters were far from diagnostic efficiency. However, it was confirmed that a fast forward and invasive examination should be performed in exudative and hemorrhagic effusions.

\section{Study Limitations}

The limitation of our study was that it did not contain sufficient information about the etiological causes of benign effusions, arising from its retrospective nature. The knowledge of etiology of benign effusion may guide the detection of false negativity rates. Since the study was retrospective, there were deficiencies in the demographic data (additional diseases, smoking history) of the patients.

The strong aspect of our study was that it contributed to data which are known to be insufficent in our country in this field.

\section{Conclusion}

Pleural effusion in patients with lung cancer is more likely to be malignant in females with an advanced age, with effusion localized in the right, with exudative and hemorrhagic effusion and with adenocarcinoma cell type. Apart from invasive methods, studies investigating biochemical markers that will detect metastatic pleural effusions will contribute to the elimination of diagnostic difficulties in this area.

\section{Ethics}

Ethics Committee Approval: This study was approved by the University of Health Sciences, İzmir Dr. Suat Seren Chest Diseases and Chest Surgery Training and Research Hospital, Clinic of Chest Diseases (number: 49109414/806.02.02).

Informed Consent: Because this study was a retrospective, informed consent form was not obtained.

Peer-review: Externally peer-reviewed.

\section{Authorship Contributions}

Concept: S.D., Design: S.D., Data Collection or Processing: Z.G., Analysis or Interpretation: S.D., Literature Search: J.Ç.E., Y.A., Writing: S.D., D.A., A.E.E.
Conflict of Interest: No conflict of interest was declared by the authors.

Financial Disclosure: The authors declared that this study received no financial support.

\section{References}

1. Erişkinlerdeki Tek Taraflı Plevral Efüzyonların Araştırılması: Britanya Toraks Derneği Plevral Hastalıklar Kılavuzu 2010:10-6.

2. Göğüs Hastalıkları Uzmanları için Plevra Hastalıkları Tanı ve Tedavi Rehberi 2016:1-3.

3. Yu H. Management of pleural effusion, empyema, and lung abscess. Semin Intervent Radiol 2011;28:75-86.

4. Light RW. Pleural Diseases 5th edition. Philadelphia: Wolter Kluwer, 2007.

5. NCCN Guidelines Version Non Small Cell Lung cancer 6. 2017. https://www.nccn.org/professionals/physician_gls/f_guidelines.asp

6. Gurung P, Goldblatt MR, Huggins JT, Doelken P, Sahn SA. Pleural fluid characteristics of paramalignant effusion. Chest 2009; 136:44S-c5S.

7. Stathopoulos GT, Kalomenidis I. Malignant pleural effusion: tumor-host interactions unleashed. Am J Respir Crit Care Med 2012;186:487-92.

8. Light RW. Pleural Effusions Releated to Metastatic Malignancies. In Pleural Diseases, 5th ed. Philadelphia, PA 19106 USA: Lippincott Williams \& Wilkins; 2007:133-61.

9. Verma A, Abisheganaden J, Light RW. Identifying Malignant Pleural Effusion by A Cancer Ratio (Serum LDH: Pleural Fluid ADA Ratio). Lung 2016;194:147-53.

10. Ong KC, Indumathi V, Poh WT, Ong YY. The diagnostic yield of pleural fluid cytology in malignant pleural effusions. Singap Med J 2000;41:19-23.

11. Koşar F. Malign Plevral Efüzyona Yaklaşım Güncel Gögüus Hastalıkları Serisi 2013;1:108-14.

12. Crnjac A, Sok M, Kamenik M. Impact of pleural effusion $\mathrm{pH}$ on the efficacy of thoracoscopic mechanical pleurodesis in patients with breast carcinoma. Eur J Cardiothorac Surg 2004;26:432-6.

13. Heffner JE, Klein JS. Recent advances in the diagnosis and management of malignant pleural effusions. Mayo Clin Proc 2008;83:235-50.

14. Gönlügör T, Gönlügör U. 454 Plevral Efüzyonun Retrospektif Analizi. İnönü Üniversitesi Tıp Fakültesi Dergisi 2007;14:21-5.

15. British Thoracic Society Pleural Disease Guideline 2010. Thorax 2010;65:(Suppl 2).

16. Lee YC, Light RW. Management of malignant pleural effusions. Respirology 2004;9:148-56. 